\title{
Letter to the editor: Comments on 'A six-weekly dosing schedule for pembrolizumab in patients with cancer based on evaluation using modelling and simulation'
}

\author{
Meta H.M. Diekstra ${ }^{\text {a,* }}$, Ruben Malmberg ${ }^{a}$, Stefan Sleijfer ${ }^{b}$, \\ Roelof W.F. van Leeuwen ${ }^{\mathrm{a}, \mathrm{b}}$ \\ a Department of Clinical Pharmacy, Erasmus University Medical Center, Rotterdam, the Netherlands \\ ${ }^{\mathrm{b}}$ Department of Medical Oncology, Erasmus MC Cancer Institute, Rotterdam, the Netherlands
}

Received 23 June 2020; accepted 2 July 2020

\section{Dear Editor,}

With great interest, we read the research article of Lala et al. [1]. The authors present a robust population pharmacokinetic (PPK) model of pembrolizumab with data from 2993 patients and a thorough data interpretation. This research gives a better insight into the exposure--response relationship for pembrolizumab, and they concluded that a dose of $2 \mathrm{mg} / \mathrm{kg}$ or a fixed dose of $200 \mathrm{mg}$ every 3 weeks (Q3W) can be extended to a dose of $400 \mathrm{mg}$ Q6W based on pharmacokinetic modelling. Although this study provides clear dosing

DOI of original article: https://doi.org/10.1016/j.ejca.2020.02.016.

* Corresponding author: Erasmus University Medical Center, Department of Clinical Pharmacy, Post box 2040, Na-219, 3000 CA, Rotterdam, the Netherlands.

E-mail addresses: m.h.m.diekstra@erasmusmc.nl (M.H.M Diekstra),r.malmberg@erasmusmc.nl (R. Malmberg), s.sleijfer@ erasmusmc.nl (S. Sleijfer), r.w.f.vanleeuwen@erasmusmc.nl (R.W.F. van Leeuwen). guidelines, a solid pharmaco-economic analysis was left underexposed to our surprise. Pharmaco-economic analyses are crucial because, in addition to being effective and safe, appropriate and cost-effective dosing should also be a part of our daily clinical practice, aiming for effective allocation of available resources in oncology $[1,2]$.

The proven feasibility of a six-weekly fixed dosing interval suggests that a six-weekly weight-based dosing strategy must be feasible as well (i.e. $4 \mathrm{mg} / \mathrm{kg}$ Q6W with a $400 \mathrm{mg}$ maximum). In addition, previously it was shown that weight-based dosing of pembrolizumab is not only equally effective and safe but also more costeffective [3-5].

In the initial studies with pembrolizumab, its benefit has been demonstrated in which it was administered as a weight-based dose of $2 \mathrm{mg} / \mathrm{kg} /$ dose Q3W. For reasons of simplification of dosing regimens, this was later adjusted to a fixed dose of $200 \mathrm{mg}$ Q3W in the summary of product characteristics. This adjustment was based on a modelling study by Freshwater et al. showing similar 
Table 1

Differences in pembrolizumab dosing methods based on 2019 patient population.

\begin{tabular}{|c|c|c|c|c|c|}
\hline \multirow{2}{*}{ Body weight } & \multirow[b]{2}{*}{ Number of prepared IV bags ( $\%$ of total) $* * *$} & \multicolumn{2}{|c|}{ Body weight and dose capping* } & \multicolumn{2}{|l|}{ Fixed dose } \\
\hline & & $\begin{array}{l}\text { Pembrolizumab dose } \\
\rightarrow \text { rounded dose }\end{array}$ & $\begin{array}{l}\text { Total number } \\
\text { of vials** }\end{array}$ & $\begin{array}{l}\text { Pembrolizumab } \\
\text { dose }\end{array}$ & $\begin{array}{l}\text { Total number } \\
\text { of vials** }\end{array}$ \\
\hline$\leq 55 \mathrm{~kg}$ & $36(8,53 \%)$ & $\leq 220 \mathrm{mg} \rightarrow 200 \mathrm{mg}$ & 2 & $400 \mathrm{mg}$ & 4 \\
\hline $55-82,5 \mathrm{~kg}$ & $231(54.74 \%)$ & $220-330 \mathrm{mg} \rightarrow 300 \mathrm{mg}$ & 3 & $400 \mathrm{mg}$ & 4 \\
\hline$\geq 82,5 \mathrm{~kg}$ & $155(36.73 \%)$ & $\geq 330 \mathrm{mg} \rightarrow 400 \mathrm{mg}$ & 4 & $400 \mathrm{mg}$ & 4 \\
\hline \multicolumn{2}{|c|}{ Total number of used vials ( $\%$ reduction versus $400 \mathrm{mg}$ fixed) } & & $1385(-18 \%)$ & & 1688 \\
\hline
\end{tabular}

$\mathrm{IV}=$ intravenous.

* Weight-based dosing with $4 \mathrm{mg} / \mathrm{kg} /$ dose to a maximum dose of $400 \mathrm{mg}$ (dose cap) and rounding using a $\pm 10 \%$ margin.

** KEYTRUDA $25 \mathrm{mg} / \mathrm{ml}$ concentrate for solution for infusion, $4 \mathrm{ml}$ vial (€2860.57 per vial; Dutch standard drug price) [7].

*** Based on total 2019 pembrolizumab administrations.

exposure distributions across the body weight range studied [4-6].

In the introduction Lala et al. [1] start with mentioning that it may be possible to conclude that a new dose regimen is effective and safe solely based on pharmacokinetic data because of the continuity of dose-response relationships, which means that information on the efficacy of a single dose (regimen) is relevant for the efficacy of another dose (regimen). In such cases pharmacokinetic parameters are constant, and this supports our conviction that a pembrolizumab dose of $2 \mathrm{mg} / \mathrm{kg}$ Q $3 \mathrm{~W}$ can be equated to $4 \mathrm{mg} / \mathrm{kg} /$ dose Q6W with similar exposure distributions based on the PK model of Lala et al. [1].

Lala et al. [1] examined the predicted efficacy and safety of $400 \mathrm{mg}$ Q6W by matching the predicted $\mathrm{C}_{\mathrm{avg}}$, $\mathrm{C}_{\min }$ (efficacy) and $\mathrm{C}_{\max }$ (safety) values with data from multiple clinical trials in which multiple dosing regimens were studied (2 mg/kg Q3W, $200 \mathrm{mg} \mathrm{Q3W}$ and $10 \mathrm{mg} / \mathrm{kg}$ Q2W). Obviously $4 \mathrm{mg} / \mathrm{kg}$ Q6W would result in $\mathrm{C}_{\max }$ values below $10 \mathrm{mg} / \mathrm{kg}$ Q2W, but we expect comparable $\mathrm{C}_{\text {avg }}$ values compared with $2 \mathrm{mg} / \mathrm{kg} \mathrm{Q} 3 \mathrm{~W}$ because the model predicts no significant differences in $\mathrm{C}_{\mathrm{avg}}$ between $200 \mathrm{mg}$ Q3W and $400 \mathrm{mg}$ Q6W. We wonder why Lala et al. did not study whether the $2 \mathrm{mg} / \mathrm{kg}$ Q3W dose can be converted to $4 \mathrm{mg} / \mathrm{kg}$ Q6W, which can be easily examined by performing an additional run on the same population to predict the efficacy and safety of $4 \mathrm{mg} / \mathrm{kg}$ Q6W or by making the script of this PPK model available. We do expect that $4 \mathrm{mg} / \mathrm{kg}$ Q6W, even as $400 \mathrm{mg}$ Q6W, will result in a small percentage of patients $(<1.0 \%)$ with transiently lower $\mathrm{C}_{\text {min.ss }}$ values. However, this period will be shorter than seven days, ensuring maintained target saturation and sufficient efficacy in this small group of patients [1].

Therefore, we propose a new six-weekly weight-based dosing regimen with a doubled weight-based dose of $4 \mathrm{mg} / \mathrm{kg}$ and a maximum dose of $400 \mathrm{mg}$. This could make six-weekly dosing of pembrolizumab much more cost-effective. In Table 1 we illustrated the different dosing methods and their corresponding costs and required number of vials. On an annual basis, $4 \mathrm{mg} / \mathrm{kg}$ Q6W dosing has a major impact on drug cost savings $[3,7,8]$. In the Erasmus MC the average body weight of patients treated with pembrolizumab is $76 \mathrm{~kg}$. Adoption of this regimen in our hospital has resulted in an $18 \%$ reduction in the number of vials used, and this has led to annual savings of approximately $€ 900,000$ euros without vial sharing. Moreover, application of the vial sharing method could provide even greater savings (up to $25 \%$ vial reduction annually) by reusing the remainder of used vials for the preparation of the next dose of the same drug. Because of the physicochemical stability of pembrolizumab (at least 7 days at room temperature) the vial sharing method seems a feasible option [9].

In our clinical setting we, therefore, customised the dose to $4 \mathrm{mg} / \mathrm{kg}$ Q6W with a maximum of $400 \mathrm{mg}$ (dose capping) with a dose rounding within a $\pm 10 \%$ margin. In this way we provide a safe and effective treatment for oncology patients with a six-weekly dosing interval and improved cost-effectiveness.

Dosing based on body weight provides significant cost savings while maintaining safety and efficacy. For the future, we expect that our proposed measurements will become even more vital because pembrolizumab will probably be registered for more indications. In addition, although it is unclear from the report of Lala et al., hopefully the Q6W schedule can also become applicable for combination therapies of pembrolizumab with other anticancer agents. In our opinion, dosing of pembrolizumab based on body weight with a capped dose of $400 \mathrm{mg}$ represents a more responsible approach than the fixed dosing regimen. Mainly because of a continuing rise in healthcare costs, optimisation of dosing strategies of expensive drugs such as pembrolizumab becomes more apparent. The aforementioned method may provide a tool for more efficient dosing and should lead to major reduction in healthcare costs. 


\section{Conflict of interest statement}

None declared.

\section{References}

[1] Lala M, Li TR, de Alwis DP, Sinha V, Mayawala K, Yamamoto $\mathrm{N}$, et al. A six-weekly dosing schedule for pembrolizumab in patients with cancer based on evaluation using modelling and simulation. Eur J Canc 2020;131:68-75. https: //doi.org/10.1016/j.ejca.2020.02.016.

[2] The ASCO Post, News item 4/29/2020, accessed on April 30, 2020, available on: https://ascopost.com/issues/may-25-2020/fdaapproves-new-pembrolizumab-dosing-regimen/.

[3] Bayle A, Besse B, Annereau M, Bonastre J. Switch to antiprogrammed cell death protein 1 (anti-PD-1) fixed-dose regimen: what is the economic impact? Eur J Canc 2019;113:28-31. https: //doi.org/10.1016/j.ejca.2019.02.016.

[4] Pembrolizumab Summary of Product Characteristics, accessed on May 6, 2020, available on: https://www.ema.europa.eu/en/ documents/product-information/keytruda-epar-productinformation_en.pdf.

[5] Pembrolizumab U.S. Food \& Drug Administration (FDA) prescribing information, accessed on May 6, 2020, available on: https://www.accessdata.fda.gov/drugsatfda_docs/label/2020/ 125514s059s064s076s0831bl.pdf.

[6] Freshwater T, Kondic A, Ahamadi M, Li CH, de Greef R, de Alwis D, et al. Evaluation of dosing strategy for pembrolizumab for oncology indications. J Immunother Canc 2017;5(43). https: //doi.org/10.1186/s40425-017-0242-5.

[7] Dutch database on drug pricing and reimbursement of medicines, accessed on May 6, 2020, available on: https://www. medicijnkosten.n1/.

[8] Vokinger KN, Hwang TJ, Grischott T, Reichert S, Tibau A, Rosemann T, et al. Prices and clinical benefit of cancer drugs in the USA and Europe: a cost-benefit analysis. Lancet Oncol 2020;21(5): 664-70. https://doi.org/10.1016/S1470-2045(20)30139-X.

[9] Sundaramurthi P, Chadwick S, Narasimhan C. Physicochemical stability of pembrolizumab admixture solution in normal saline intravenous infusion bag. J Oncol Pharm Pract 2019;26:641-6. https://doi.org/10.1177/1078155219868516. 